UN IVERSITY OF COPENHAGEN

\title{
Seeing what I am doing
}

Grünbaum, Thor

Published in:

Philosophy and Phenomenological Research

DOI:

10.1111/j.1933-1592.2012.00647.x

Publication date:

2013

Document version

Peer reviewed version

Citation for published version (APA):

Grünbaum, T. (2013). Seeing what I am doing. Philosophy and Phenomenological Research, 86(2), 295-318. https://doi.org/10.1111/j.1933-1592.2012.00647.x 
Final draft. Grünbaum, T. (2013). Seeing what I am doing. Philosophy and Phenomenological Research, 86(2), 295-318. DOI: 10.1111/j.1933-1592.2012.00647.x

\title{
Seeing what I am doing
}

Thor Grünbaum (Philosophy, University of Copenhagen)

\begin{abstract}
I argue against the view that an agent's knowledge of her own current action cannot in any way rely on perception for its justification. Instead, I argue that when it comes to an agent's knowledge of her own object-oriented intentional action, the agent's belief about what she is doing is partly justified by her perception of the object of action. I proceed by first proposing an account of such actions according to which the agent's knowledge is partly justified by her perception. I then discuss several of objections to my proposal. The most important objection is that I have only managed to show that perception plays an enabling role and not a justificatory role for the agent's knowledge of her own intentional action
\end{abstract}

\section{Introduction}

Many philosophers think that an agent's knowledge of her own intentional action is non-observational. In an intuitive way this seems correct. As agents we do not need to study or look at ourselves or scrutinize the changes our actions bring about in the world in order to know what we are doing. Some philosophers take these innocuous intuitions a step further. They think that the agent's knowledge of her own action is constitutive of its being an intentional action. That is, they think that an agent's action is intentional only if the agent has some knowledge of relevant aspects of her own action. If you think this, then maybe you will find it obvious that the agent's knowledge could not be observational. If the agent's knowledge is constitutive, it must be knowledge had in the act or even before the act. Perception of one's own action or of the effects of one's action seems to be had after the act - inspection of consequences. So, the epistemic status of agent's belief about her own intentional action is independent of her perceptual experience.

In this paper, I want to question the correctness of this claim. My strategy will be as follows. First, I will state more clearly which claim I want to question (section 2). Second, I will present a type of case where perception plays an essential role. I will argue that in this type of case perception plays a justificatory role in relation to the agent's knowledge of her own current intentional action (section 3). Third, I will reply 
Final draft. Grünbaum, T. (2013). Seeing what I am doing. Philosophy and Phenomenological Research, 86(2), 295-318. DOI: 10.1111/j.1933-1592.2012.00647.x

to a number of objections; the most important being that I have only managed to show that perception plays a crucial and ineliminable enabling role for the agent's knowledge (section 4). Finally, I will conclude by summing up the main points of my argument (section 5).

\section{Non-observational knowledge}

Contemporary discussions of how an agent knows her own action are shaped by a number of ideas and concerns introduced by G.E.M. Anscombe in her book Intention (2000). Without getting entangled in exegetical issues, we can think of Anscombe's account of agents' knowledge as characterized by the following two claims (see Paul 2009):

2.1. An agent's knowledge of her own action is the cause of what she knows, viz. the action (Anscombe 2000: 56-57, 88).

2.2. An agent's knowledge of her own action is non-observational, i.e. an agent does not in any way rely epistemically on observational evidence when she knows what she doing (op.cit. 13).

With (2.1) Anscombe wanted to express the idea that agents' knowledge is a very special form of practical knowledge to be distinguished from ordinary speculative knowledge. Anscombe famously claimed that the agent's knowledge is a special form of knowledge not governed by normal epistemic standards (such as, if the world is not as one believes it to be, then one does not know). With (2.2) she wanted to articulate the idea that some things can be known without relying on sensory evidence or other forms of empirical evidence. Included in the class of non-observational knowledge, we find the way in which a person ordinarily knows the position of her limbs, mathematical knowledge, a priori analytical knowledge, and knowledge of one's own intentional action.

Contemporary Anscombeans do not accept Anscombe's version of (2.1). Rather, they take it to mean that an agent can know what she is intentionally doing simply by knowing what she intends to do 
Final draft. Grünbaum, T. (2013). Seeing what I am doing. Philosophy and Phenomenological Research, 86(2), 295-318. DOI: 10.1111/j.1933-1592.2012.00647.x

(or intends to be doing). ${ }^{1}$ The obvious problem for such a view is that sometimes an agent intends to $\phi$ but does not succeed in $\phi$-ing. An agent might even intend to do something she has only a small chance of succeeding in doing. In such cases, the agent does not seem to be entitled to judge that she is $\phi$-ing merely on the basis of her knowledge of intending to $\phi$. The familiar response to such worries is to restrict the idea of knowledge in intention to a specific class of intentions. The common rational for such a restriction is the idea that when an agent engages in some action in which she has a very low degree of confidence in succeeding, she will normally do the action by doing something in which she does have some (sufficiently high) degree of confidence. The common response is thus to say that an agent is entitled to grasp her intention as a description of her action only if the intention is basic (that is, an intention to do an action that the agent can perform as a basic action). ${ }^{2}$ Consequently, many contemporary Anscombeans interpret (1) in the following way:

\footnotetext{
${ }^{1}$ See Falvey (2000): "in offering this [an expression of his intention] in answer to the question about what he is doing the agent is presenting his expression of intention as, simultaneously, a description of what he is doing" (p. 23); "my knowledge of the latter fact [that I am making bread] simply consists, at least during such periods, in my knowledge of the former [that I intend to be making bread]" (p. 25); "My right to assume that the program [motor skills] is running properly gives me the right to employ this expression of intention as a description of what I am doing" (p. 35). Peacocke (2003): “when a thinker has a distinctive awareness of trying to $\phi$, where $\phi$-ing is basic for him, he is entitled to judge that he is $\phi$-ing" (p. 107). Related claims are to be found in O'Brien (2007: ch. 9). The view is also found in Intention where Anscombe claims that what an agent is doing is "known by being the content of intention" (Anscombe 2000: 53).

${ }^{2}$ For this restriction, see Peacocke (2003): "This point holds for a range of kinds of tryings which are a subset of those which are basic actions for the agent in question" (p. 107); O'Brien (2007): “The claim of first-person authority with respect to our actions is to be understood as relative to certain descriptions that can be regarded as basic" (p. 189). Setiya (2008): “A consequence of this principle is that basic intentional actions - one's that are not done by doing anything else intentionally - must be accompanied by belief" (p. 390, italics in original). Falvey (2000) restricts the
} 
Final draft. Grünbaum, T. (2013). Seeing what I am doing. Philosophy and Phenomenological Research, 86(2), 295-318. DOI: 10.1111/j.1933-1592.2012.00647.x

2.3. Assuming certain background conditions hold (skills, know-how, a minimally cooperative world), the agent is entitled to grasp the content of her intention to do a basic action as a description of her intentional action.

The agent's intention is a cause of her action. Knowledge of intention can therefore be said to be the cause of what is known, viz. the action. For the remainder of the present paper I will assume (2.3) to be true as an account of how an agent knows her own intentional action under its most basic description: she knows by knowing what she intends to do (or intend to be doing). Contrary to what is commonly assumed, from the acceptance of (2.3) it does not follow that the agent's knowledge is non-observational. In any case, this is what I will argue in this paper.

Intuitively, it looks like a good explanation of how an agent knows what she is doing without observation that she knows it by simply knowing her intention. ${ }^{3}$ An additional premise is, however, required, namely one saying that an agent has non-observational knowledge of her own intention. It is exactly this extra premise I am denying, at least if it is thought to have a completely general scope. My main claim is that in one central type of case, we should accept that an agent's knowledge of what she intends to be doing is partly justified by her perceptual experience.

The idea that the non-observational character of knowledge of action is explained by the non-observational character of knowledge of intention can be articulated as the following pair of conditionals:

relevant class of intentions to "intentions-to-be- $\varphi$-ing" (p. 23) which are not unlike Searle's (1983) "intention-inaction".

${ }^{3}$ See, for example, Falvey (2000): "I take it as a fundamental datum that under normal circumstances, an agent in the midst of acting can typically provide a correct answer to the question, 'what are you doing?' straight off, without relying on observation or inference. I suggest that this is possible because the answer he gives, 'I am $\phi$-ing', is an expression of what he intends to be doing" (p. 22-23, italics in the original). 
Final draft. Grünbaum, T. (2013). Seeing what I am doing. Philosophy and Phenomenological Research, 86(2), 295-318. DOI: 10.1111/j.1933-1592.2012.00647.x

2.4. If knowledge of intention is non-observational, then knowledge of action is non-observational.

2.5. If knowledge of intention is observational, then knowledge of action is observational.

The point is this. If we accept the idea that, with respect to basic actions, the agent knows her action by knowing her intention, then the agent's knowledge of action is non-observational because her knowledge of intention is non-observational. Had the knowledge of intention not been non-observational, then the knowledge of action would not have been non-observational. In this paper, I argue that, for one type of intention, we ought to accept that agents can know what they intend to be doing only because of their perceptual experience. If we accept the conditionals ( $2.4 \& 2.5)$, this type of intention therefore provides us with material for an objection to the contemporary Anscombean account of agents' knowledge.

\section{Demonstrative intentions}

Let us begin with an example. Imagine that you are at a market and want to buy a delicious apple. You are standing at the greengrocer's fruit wagon inspecting a nice pile of apples. You are looking for the apple you want to buy and eat. That is, you are searching for an apple with just the right constellation of properties. On finding the one you want, you pick it up (and hand it to the greengrocer).

I want to argue that in cases such as this perception plays a justificatory role for the agent's knowledge of her own action. I do not want to suggest that it is only on the basis of perception that the agent knows what she is doing. I want to argue that it is partly on the basis of her perception that she is justified in her belief about what she is doing. My claim is that in so far we can say that the agent's intention is her intention to pick up this apple and that her intentional action is the action of picking up this apple (the apple demonstratively presented to the agent), we have to admit that the agent knows what she is doing partly on the basis of her perceptual attention to the object involved in her intentional action.

First, we will have to settle on an appropriate level of description of the agent's intentional action. An agent's action can be intentional under a variety of descriptions ranging from very general and unspecific descriptions to detailed and specific descriptions. Anscombe $(1979,2000)$ argued that the way in 
Final draft. Grünbaum, T. (2013). Seeing what I am doing. Philosophy and Phenomenological Research, 86(2), 295-318. DOI: 10.1111/j.1933-1592.2012.00647.x

which various action-descriptions (descriptions under which one's action is intentional) of one and the same piece of behaviour are related to each other is determined by the agent's practical reasoning. Her idea was that a series of why-questions (asking for a reason for one's action) can be repeatedly answered by stating one's aim in acting: "why did you stretch your body like that?" - "I was taking down a book from the top shelf". "Why were you taking down a book?" - "I was going to read a section in it". "Why were you going to read a section in it?" - "I was preparing a talk for a conference". Anscombe argued that these "inorder-to"-relations can be regarded as the reversed image of the steps of the agent's practical reasoning: "In preparing my talk I need to read this section, and if I want to read this section, I need to get the book, and I can only get the book by finding it on the shelf and taking it down". Thus, for Anscombe, one important form of practical reasoning is a procedure by which the agent beginning from a general aim - an intention too general to be acted immediately upon - "calculates" what she can do directly in order to achieve or realize her aim (Anscombe 2000: 78).

The most immediate or basic description under which an agent's behaviour is intentional is thus determined by her practical reasoning: it is where her reasoning ends and her action begins because she no longer has to "calculate" how to perform her action (that is, how to achieve her goal). A basic action-description singles out her behaviour as an intentional goal-striving in which she can engage without thinking about how to do it. In other words, it singles out her action as a skill or as her skilful behaviour. You can stop reasoning and start acting when the goal you intend to reach or achieve is something you are skilled at reaching or achieving. ${ }^{4}$

\footnotetext{
${ }^{4}$ In this paper, I remain neutral on the issue of action individuation. I will thus set aside the question of whether action descriptions should be individuated in a fine grained (Goldman 1971) or coarse grained (Anscombe 1979, Davidson 1980, Essay 3 and 6, and Hornsby 1980) or an in-between (Ginet 1990: ch. 3) way. With respect to these issues, like Ginet (1990: 70), I think nothing much depends on one's choice of theory: "[...] there is no other significant question in the philosophy of action that depends on it." I therefore feel free to use "action-talk" and "description-talk" interchangeably.
} 
Final draft. Grünbaum, T. (2013). Seeing what I am doing. Philosophy and Phenomenological Research, 86(2), 295-318. DOI: 10.1111/j.1933-1592.2012.00647.x

Accepting this relationship between practical reasoning and action-descriptions, several authors (e.g. Hornsby 1980, ch. 6, and Enç 2003, ch. 2) have suggested the following way of defining the basicness of the agent's intentional action in terms of the agent's practical reasoning:

An agent's act of doing $B$ is basic if and only if:

3.1. The agent knows how to do $B$

3.2. In her performance of $B$, the agent uses her knowledge of how to do $B$, and

3.3. The agent is not performing an action $A$ such that

a. The agent knows how to do $A$, and

b. In order to do B, the agent needs to explicitly use her knowledge of how to do A.

This is not supposed to be a definition of intentional action. Rather, it is supposed to state necessary and sufficient conditions for basicness. It gives us the following necessary condition on action descriptions: if an agent's behaviour can be described as her intentional action, then either it is her basic action or it depends (in some way) on her basic action. On a given occasion, there will be no description below the level of basic action that could count as the agent's intentional action. That is, an agent might be able to flex particular muscles and form a particular grip with her fingers (imitate all the movements one would need to make in order to pick up an apple) as basic actions but on this occasion when picking up a particular apple, picking it up is her basic action and all the individual movements are not (since she is not making explicit use of her knowledge of how to make movements in this particular way in order to pick up the apple). If we accept (2.3), the relevant intentions are determined by the agent's skills and her practical reasoning in a given context.

Take our example. One plausible way, I submit, to construe the practical reasoning of an agent standing in front of a pile of apples searching for the right one would be as follows. I want the most appealing apple and the most appealing one looks like (...); this apple looks like (...); I want this apple. And 
Final draft. Grünbaum, T. (2013). Seeing what I am doing. Philosophy and Phenomenological Research, 86(2), 295-318. DOI: 10.1111/j.1933-1592.2012.00647.x

the agent proceeds to pick it up (let's imagine that the apple is at the top of the pile and easy to pick up). Let us stipulate that the "wants" are more than just expressions of the agent's desire or wish; they are expressions of her commitment to act. That is, they express her intention to pick up the apple. We could then give this practical reasoning a philosophical gloss and render it as follows:

\subsection{Prior intention: I shall pick up the most appealing apple.}

3.5. Visual attentional search and identification of the most appealing apple as this particular apple.

3.6. Demonstrative intention: I shall pick up this apple.

Barring cases with abnormal psychological, physical, and environmental conditions, this demonstrative intention is one the agent can carry out without having to deliberate about how to do it. Picking up this apple is her basic intentional action.

On finding the most appealing apple, the agent selects it for action, and in selecting it, she lets this particular apple specify her prior intention (3.4). By visually selecting the identified object for action, she forms an intention specific enough to act on: the intention to pick up this apple. From the demonstrative intention parameters for control of her motor action can be computed: in selecting the object, norms are set up for the right preshaping of fingers, generation of force and speed, etc. In visually selecting the object for action, she moves from a prior intention too general to be acted upon to an intention specific enough to guide and control her behaviour (from "grasp the most appealing apple" to "grasp this apple").

In more general terms the proposal is this. Usually when acting manipulatively on objects in our environment, intentions which make general or descriptive reference to objects of action are often not

\footnotetext{
${ }^{5}$ By the notion of prior intention I am not committing myself to any specific account of content and function of intention. I am merely saying that some intentions are prior to action because they are too general to guide and sustain the agent's intentional behaviour. This characterization does not exclude the possibility of acting intentionally without any prior deliberation or prior intention.
} 
Final draft. Grünbaum, T. (2013). Seeing what I am doing. Philosophy and Phenomenological Research, 86(2), 295-318. DOI: 10.1111/j.1933-1592.2012.00647.x

specific enough to initiate and guide our actions. Intentions to throw the paper in the waste basket or to writes one's signature on some form are not specific enough. The agent needs to know which particular object is the basket or form in question before she can initiate her action. We can think of perceptual attention as having the role of selecting the right object in the world and thereby specifying the prior intention. The role of attention is to transform the prior intention (too unspecific to initiate and guide action) into a demonstrative intention: the intention to $\varphi$ with this ${ }^{6}{ }^{6}$

In many cases the agent cannot execute her intention without forming a demonstrative intention. That is, without forming an intention in the content of which a demonstrative picks out an object towards which the action is oriented. It is the way in which these demonstratives rely on perceptualattentional identification which is important and not as such the fact that the reference to the object is direct and non-descriptive. To appreciate this point, consider intentions that refer to an object of action with an indexical concept like my. ${ }^{7}$ Just like the case of intentions with descriptive content (e.g. the most delicious apple), in order to be executed, indexical intentions also rely on perceptual-attentional identification and selection of the right particular in the world. It is helpful, in this context, to recall Kaplan's distinction between pure indexicals and demonstratives (Kaplan 1989a). Pure indexicals are expressions like "I", "my", "today", and "tomorrow". According to Kaplan, the reference of pure indexical expressions uttered in a particular context is fixed automatically by simple reference rules. The reference of "my cup" would, for example, be fixed automatically by a rule like: the cup belonging to the utterer of the expression. By contrast, the reference of true demonstratives like "he", "she", "his", "her", "this", and "that" is not fixed automatically in particular contexts. In the case of demonstratives, the reference depends on

\footnotetext{
${ }^{6}$ In the psychological literature we find a number of proposals stressing the idea that the function of selective attention is to control behaviour. See, for example, Allport (1993), Neumann (1990), Styles (1997: ch. 6-9) and Hommel (2005).

${ }^{7}$ I mention concepts and thoughts by italics.
} 
Final draft. Grünbaum, T. (2013). Seeing what I am doing. Philosophy and Phenomenological Research, 86(2), 295-318. DOI: 10.1111/j.1933-1592.2012.00647.x

cognitive acts of demonstration by the utterer. As Kaplan writes, the reference in a context is fixed by demonstration and demonstration is "typically directed by the speaker's intention to point at a perceived individual on whom he has focused" (1989b: 582). We can transfer this insight from the domain of linguistic utterances to thoughts. Linguistic demonstration depends on mental demonstration which in turn depends on perceptual attention to particular objects.

The important point to bring out in this context is that some intentions rely on perceptual identification of the right object. In the right conditions, standing at a bar, forming the intention to drink from my glass, the pure indexical concept my will automatically refer to one of the many glasses on the desk. But this will not in itself enable me to pick up the right glass. The pure indexical will refer to which ever glass I was given by the bartender when I purchased a drink whether or not I know which glass is mine. This intention does not tell me which of the glasses to pick up. It can therefore not be used in control of my behaviour. I need to select an object of action. Once I have perceptually identified the particular I can form the demonstrative intention to act on it. The demonstrative in the content of the demonstrative intention is locked to perceptual identification of a particular object. It is this perceptual-attentional identification that delivers the content of the demonstrative.

So, the claim here is that often prior intentions (like 3.4 above) are not specific enough to initiate and guide an agent's action, and that the agent uses perceptual attention to locate the right object in order to derive or specify an intention (a demonstrative intention like 3.6) with the right degree of specificity to initiate and guide her action.

This account of the execution of demonstrative intentions as the agent's basic intentional action has implications for how we should think of the epistemic role of perception in the agent's knowledge. In our example, the agent's basic intentional action is her execution of her demonstrative intention to pick up this apple. According to many contemporary accounts of agents' knowledge, an agent knows her own intentional action by grasping the content of her intention as a description of her action. Grasping the content of a demonstrative intention requires that the agent knows which object the 
Final draft. Grünbaum, T. (2013). Seeing what I am doing. Philosophy and Phenomenological Research, 86(2), 295-318. DOI: 10.1111/j.1933-1592.2012.00647.x

demonstrative is referring to. For an agent in cases such as these, it is crucial that it is the particular in the world she is looking at that is the object involved in her intention. It is this particular that she intends to act on, not some other particular. The meaning of the demonstrative in the content of her intention is given by the object she is perceptually attending to when forming the intention. She can only know which object in the world she intends to do something with by locating it and selecting it perceptually. She could not have nor understand the demonstrative intention if it was not for her perception of the object.

Imagine a person standing at a bar. She wants to drink from her glass, looks around for it, and on finding it forms the demonstrative intention to drink from this glass. How does she know that she intends to drink from this one rather than that one? Well, this is the one she is looking at. How does she know that she is drinking from this glass and not some other glass (maybe her hand has not yet grasped the glass and a qualitative indistinguishable glass is standing right next to it)? Again, this glass is the one she is attending to. Perception is therefore not only what enables her to form and execute the intention but is part of what justifies her claim to know what she intends to do and is engaged in doing.

Like a proponent of the non-observational account I propose that the agent knows what she is doing by knowing the content of her demonstrative intention but on my account the intention is demonstrative only by its distinctive relation to the agent's perceptual-attentional experience and the agent would have no knowledge or be justified if it were not for her perceptual-attentional experience. In brief, my proposal is that, with respect to her basic action, the agent is justified in believing she is executing the action specified by her demonstrative intention partly in virtue of her perceptual-attentional experience of the object of action. The reason is that the object is part of what individuates her intention and thereby her action, and the agent will only be justified in her belief about which particular intention she is executing if she is standing in the right experiential-attentional relation to the object. She is justified in grasping the content of her demonstrative intention as a description of her action partly because of her perceptual knowledge of which object she is acting on. 
Final draft. Grünbaum, T. (2013). Seeing what I am doing. Philosophy and Phenomenological Research, 86(2), 295-318. DOI: 10.1111/j.1933-1592.2012.00647.x

\section{Objections and replies}

My proposal is in conflict with the contemporary Anscombean idea of non-observational knowledge of action and it will naturally be met with some resistance. Let me try to work my way through some of the most obvious and important objections to it.

\subsection{Enabling vs. justificatory roles}

For someone who wants to resist the proposal that perception plays a justificatory role in the agent's knowledge of her own basic action (her execution of a demonstrative intention), the most important objection would perhaps be to insist that all I have shown is that perceptual attention is an important and ineliminable enabling condition for the acquisition and execution of demonstrative intentions, and thereby also for the knowledge of one's own basic action. Without perceptual attention the agent could not form and execute a demonstrative intention, and consequently there would be no action for her to know. My argument does, however, not establish that perception plays any justificatory role. ${ }^{8}$

One way to understand this objection is by analogy with a priori knowledge. According to one understanding of a priori, a proposition is knowable a priori if understanding it is sufficient for knowledge of its truth (or sufficient for one's belief being justified). Candidates for this kind of knowledge are mathematical propositions like $2+5=7$ or analytical propositions like all unmarried men are bachelors. Take for instance one's knowledge that red is a colour. If a person knows the meaning of the concepts, this looks like a good candidate for a proposition that she can know a priori or be a priori justified in believing. Of course, the concept of colours has important ties with experience. It might be the case that a person cannot acquire colour concepts (concepts of particular colours and the general concept of colour) without

\footnotetext{
${ }^{8}$ For a relevant discussion of the distinction between enabling and justificatory roles, see Burge (1993) and (1998). For arguments that perception plays an enabling and not a justificatory role in agents' knowledge, see Falvey (2000) and Moran (2004).
} 
Final draft. Grünbaum, T. (2013). Seeing what I am doing. Philosophy and Phenomenological Research, 86(2), 295-318. DOI: 10.1111/j.1933-1592.2012.00647.x

experiencing colours. Still, this empiricist insight does not jettison the a priori knowledge of red is a colour. We could grant that someone with no experience at all (or of colours) could not know this. This, however, is not because experience plays any justificatory role in a priori knowledge that red is a colour. It is because without experience, a person could not acquire the concepts red and colour. Once the concepts are acquired, a person need no further experience in order to figure out that red is a colour.

To be sure, with respect to knowledge of one's own intentional actions, the analogy with a priori knowledge should not be taken too literally. If the objection is to have any genuine force, then the point of the analogy should not be to argue that an agent's knowledge of her own demonstrative intention is a form of knowledge where understanding the concepts is sufficient for understanding entailments; rather the point is that knowledge of demonstrative intention as a form of self-knowledge in one important respect is like a priori knowledge: once the concept or the content has been acquired or instantiated, perceptual experience plays no further role in justifying one's second-order belief about one's thoughts with this particular concept or content. ${ }^{9}$

The objection can be articulated like this. Let us assume that everyone accepts that beliefs are partly individuated by their contents and that perceptual demonstrative content is partly individuated by the object of conscious perceptual attention. Furthermore, let us assume that demonstrative content is object-dependent in the sense that the tokening of the content by the thinker depends on the actual presence of a particular object (being consciously experienced by the thinker). ${ }^{10} \mathrm{~A}$ person's demonstrative belief about a cup in front of her (she thinks: this cup is red) is about this particular cup because this is the cup with which she is experientially acquainted. Even if we assume this view of object-dependent demonstrative content, it is a further claim to say that perceptual experience is part of what justifies her

\footnotetext{
${ }^{9}$ Thanks to a referee for articulating this analogy with a priori knowledge. Several sentences are directly lifted out of his/her comment.

${ }^{10}$ This view is defended by Evans (1982), McDowell (1986), and Brewer (1999).
} 
Final draft. Grünbaum, T. (2013). Seeing what I am doing. Philosophy and Phenomenological Research, 86(2), 295-318. DOI: 10.1111/j.1933-1592.2012.00647.x

second-order belief that she believes something about this cup. There is a difference between accepting that a particular perceptual episode is necessary for a thought having the particular content that it has and accepting that the perceptual episode justifies a second-order belief about thinking this particular thought with its particular content.

We can also assume for the sake of argument that everyone accepts that if a person's perceptual experience of $o$ is to be part of what justifies her second-order belief about her belief about $o$, then her perceptual experience of $o$ must amount to knowledge of $o$ or yield knowledge of $o$. This means that if something were to undermine her perceptual knowledge of $o$, then her knowledge of her own belief about $o$ would be undermined as well. If my perceptual knowledge is undermined, then anything I infer from my perceptual belief will be undermined as well. Beliefs based on experience will all be unjustified. It therefore follows that if we can find a case where a person's first-order perceptual knowledge of $o$ is defeated but her second-order knowledge of her demonstrative belief about $o$ remains unharmed, then it would show that perceptual experience could not be playing a justificatory role for her second-order belief. It might, of course, still be playing an essential enabling role (without experience the first-order demonstrative belief would not have been formed in the first place).

The following situation might be such a case. Imagine a situation where I am not justified in believing that this cup is red. I know that the lighting in this room is such that all white things look red but I have momentarily forgotten. I look at the cup and think that this cup is red. This is a situation where my belief based on perception is unjustified but where I can still know that I believe that this cup is red. It looks like I can have self-knowledge even of unjustified demonstrative beliefs. Perception enables the formation of the second-order belief but it does not justify it. Importantly for the present discussion, if this is true of demonstrative beliefs, it seems to be true as well of demonstrative intentions. On seeing the cup and thinking this cup is red (having momentarily forgotten about the lighting conditions), I form the intention to grasp this red cup. My perceptual belief about the redness of this cup is unjustified but my knowledge 
Final draft. Grünbaum, T. (2013). Seeing what I am doing. Philosophy and Phenomenological Research, 86(2), 295-318. DOI: 10.1111/j.1933-1592.2012.00647.x

about my intention to grasp this red cup is unharmed. So, it looks as if experience enables the agent's formation of the demonstrative intention but does not justify her knowledge about it.

This type of case is not a real threat to my proposal that perceptual experience plays a justificatory role for the agent's knowledge of her demonstrative intentions (and therewith her own basic intentional actions). The case establishes that some forms of second-order beliefs about one's own thinking can be justified even when the first-order belief is not justified by perception. But it falls short of establishing that all forms of second-order beliefs can be justified in the absence of the perceptual justification. In the above scenario, not all types of perceptual knowledge are undermined. I might not be justified in believing that this cup is red but I am still justified in believing that this is a cup.

At this point my opponent might reply by offering a stronger type of case. Imagine that bolted to my writing desk is a pencil holder made of red steel. From a certain angle the pencil holder looks remarkably like my favourite red cup. I know about this similarity and I never mistake the two. Today, however, for some reason, I momentarily forget and while looking at the pencil holder I am thinking this cup is red. In this type of case, I am not perceptually justified in thinking that this $F$ is $G$ because the object is not $F$ and I know this and should have remembered. Again, it looks as if even though my perceptual knowledge of the cup is undermined I am still justified in believing that I think this cup is red. It seems that perception could not be playing a justificatory role for my second-order belief. If this point holds for perceptual beliefs, it would seem to carry over to the case of intentions. Imagine that I am thirsty, so I am looking for my cup. I see the pencil holder and think this is my cup and form the intention to grasp this cup. My perceptual knowledge of the cup is undermined but my second-order knowledge of my demonstrative intention is not.

But again the scenario does not establish the strong claim that all perceptual justification is undermined by my momentary lapse in memory. There is a perceptual object present on the table. Granted, because of the memory lapse I misclassify it as a cup. But this does not detract from the fact that a perceptual object is present there in front of me on the table. An object that has the form of a bounded 
Final draft. Grünbaum, T. (2013). Seeing what I am doing. Philosophy and Phenomenological Research, 86(2), 295-318. DOI: 10.1111/j.1933-1592.2012.00647.x

whole. This is the kind of visual gestalt my visual system automatically treats as if it were a physical object. Psychological evidence exists suggesting that the human visual system automatically conceive of such a bounded gestalt as being an object that cannot be at two different locations at the same time, that occupies a location uniquely (two objects cannot occupy the same location at the same time), and that travels a spatiotemporal continuous path between two locations. ${ }^{11}$ Furthermore, there is evidence suggesting that this basic concept of a physical object is not only developmentally prior to the acquisition of more advanced sortals like cup or table, but also is cognitively basic for adults in the sense that it constitutes our basic system of object-attention. Attention to visual objects moving as bounded wholes on continuous path is our basic way of relating cognitively to objects in our environment. ${ }^{12}$

One way to interpret this psychological data and applying it to the present case is as follows: Perception and gaze-direction are not sufficient for fixing the reference of the demonstrative thought. Appearance of and attention to a particular bounded gestalt that one's visual system is treating as a physical object are needed as well. Attention to a bounded visual gestalt is an important aspect of the mechanism that fixes the reference of the demonstrative. The particular bounded visual gestalt is, in other words, a crucial part of what individuates the demonstrative thought. When it comes to the mechanism responsible for fixing the reference of the demonstrative thought, there are good reasons for thinking that this basic visual way of individuating and identifying visual particulars is more important than the advanced kind sortals used to categorise the object. To use a modified example of Fei Xu's (1997: 386): Just as before, I have momentarily forgotten about similarity between the pencil holder and my cup. But I have equally forgotten that from another perspective the pencil holder resembles my late grandfather's telescope. As I move around the room I think this stream of thoughts: This is a pencil holder, no, it's my cup, no, it's the

\footnotetext{
${ }^{11}$ For a review and discussion of the psychological evidence, see Scholl (2001) and (2007).

${ }^{12}$ For reviews and discussion of evidence, see Xu (1997), Scholl \& Leslie (1999), and Carey \& Xu (2001).
} 
Final draft. Grünbaum, T. (2013). Seeing what I am doing. Philosophy and Phenomenological Research, 86(2), 295-318. DOI: 10.1111/j.1933-1592.2012.00647.x

telescope. We have no problem understanding that the demonstrative is referring to the same object (the visual object on the table) all through this train of thoughts. ${ }^{13}$

One way to describe the structure of my demonstrative belief that this cup is red is as the belief that this visual object is a cup and it is red. The situation undermines some perceptual beliefs (this is a cup, this cup is red, this cup is just in front of me) but not other perceptually justified beliefs (this thing is red, this thing is just in front of me). My suggestion is that part of what justifies my belief that I intend to grasp this cup is that I am perceptually attending to the visual object to which the demonstrative is referring. Knowledge that there is a bounded visual object on the table is not defeated in the case under discussion. In this case, I therefore have perceptual knowledge of $o$ which could be said to play a justificatory role for my knowledge of my intentional o-oriented action.

This is in line with the account of the role visual attention in practical reasoning briefly outlined above (section 3). There I suggested that one important function of visual attention is to transform the prior intention (an intention to abstract to initiate and guide action) into a demonstrative intention by selecting an object for action. Misperception can be an important source of error in this transformation. Misperceiving a white thing as red or a pencil holder as my cup could result in locating and selecting the wrong object. But once the object has been visually located and selected, I intend to grasp it. That is, I intend to grasp this object individuated by its location in egocentric space. As long as we accept the objectdependent nature of demonstrative content it therefore seems impossible to find cases where knowledge of one's own demonstrative intention to $\varphi$ with $o$ is possible in the absence of the right kind of perceptual knowledge of $o$. My second-order belief about my demonstrative intention to grasp this thing is in part justified by my perceptual experience, just not the perceptual experiences relevant to its being a cup or being red. It is the person's visual attention to the object that enables and justifies the person's belief that

\footnotetext{
${ }^{13}$ Campbell (2002) seems to be adopting this view of demonstrative content: if a person can attend to a visual gestalt and track it, then she has perceptual knowledge of the referent and can think demonstratively about it.
} 
Final draft. Grünbaum, T. (2013). Seeing what I am doing. Philosophy and Phenomenological Research, 86(2), 295-318. DOI: 10.1111/j.1933-1592.2012.00647.x

this bounded visual gestalt (the object) is present right there. When forming the intention to grasp this cup, I am also forming the intention to grasp this visual gestalt (thing). My claim is that not only is the intention enabled by my visual attention to the visual gestalt, my visual attention partly justifies my knowledge of intending to grasp this particular thing.

My opponent could object to this claim and try to argue that all I have established is that in the case of demonstrative intentions perceptual experience always enables and justifies the first-order demonstrative intention but only enables the second-order belief about the first-order demonstrative state. It is, however, at this point hard to see what might constitute a clear and strong motivation for this objection to my proposal. If in the case of demonstrative intentions the justificatory role and enabling role always occur together, then we need good reasons for assuming that they are in fact distinct capacities.

Even if we insist that the justificatory role and the enabling role of conscious visual attention can come apart also in the case of demonstrative intentions, I think this could just as well count in my favour. Consider the following scenario where the enabling role of perceptual experience is held constant but its justificatory role is manipulated. Imagine that I am sitting in front of a square and white computer screen. Located in the upper right and the lower left corners there is a red circle with a diameter of 500 $\mathrm{mm}$. The task is as follows. On hearing a first tone, the two circles will begin to move around on the screen in a random way. I have to track the circle in the upper right corner and as soon as I hear a second tone I have to touch the circle with my index finger. If I touch the upper right corner circle I win 10 Euros, but if I touch the lower left corner circle I lose 100 Euros. I therefore attend carefully to the circle in the upper right corner and form the intention to touch this thing as soon as I hear the second tone. I hear the first tone and the circles start moving. I have no problems in visually tracking the upper right corner circle as it moves randomly around on the screen. I continuously have the same intention to touch this thing as soon as I hear the second tone and I know that this is what I intend to do.

Now, someone taps me on the shoulder and tells me that just as I blinked the two circles bounced into each other (for the sake of the argument, assume this context is strong enough to defeat my 
Final draft. Grünbaum, T. (2013). Seeing what I am doing. Philosophy and Phenomenological Research, 86(2), 295-318. DOI: 10.1111/j.1933-1592.2012.00647.x

perceptual knowledge of tracking the same individual). I no longer know whether the circle to which I am now attending is the same as the one which as a start location had the upper right corner. As a consequence, I do not know whether the intention to touch this thing I had when I was tapped on the shoulder is the same I had just a few moments before (before I blinked and was successfully tracking the upper right corner circle). These demonstrative intentions are individuated by the object to which I am attending. If I am now attending to the wrong circle (the lower left corner circle), then my intention to touch this thing might not be the same as the demonstrative intention with which I started out. It matters a great deal to me which demonstrative intention I have because acting on the wrong one I end up paying 100 Euros. As long I am in doubt about which demonstrative intention I am entertaining, it will be rational for me to act as if I do not know whether my action-plan (the plan to touch this one) is the right one. I do not know which of two possible contents my action-plan is representing. When being tapped on the shoulder and informed about my blinking, I lose my demonstrative intention to touch this one (when I learn that I do not know which circle I am currently tracking, it will be rational for me to refrain from acting). The result will be that I do not know which intention I actually had just a moment ago (a moment placed between being tapped on the shoulder and blinking).

I think this is a case where background conditions defeat the agent's perceptual tracking of the individual object and thereby undermine the agent's knowledge of her demonstrative intention. My belief about my own demonstrative intention is no longer justified because I no longer have knowledge of tracking the right particular. I no longer know whether my demonstrative content is one or the other of two possible contents, and the reason I no longer know is that I have lost my perceptual knowledge of which particular I am tracking. I keep track of my demonstrative intention by keeping track of its object. If there is a stretch of time where (without knowing it) I lose track of which particular object I am in fact following, then I also (equally without knowing it) lose track of my intention. For this stretch of time (in the present scenario between being tapped on the shoulder and blinking), I do not know what I demonstratively intend to do. After being tapped on the shoulder, thinking back on this stretch of time, I must acknowledge that I 
Final draft. Grünbaum, T. (2013). Seeing what I am doing. Philosophy and Phenomenological Research, 86(2), 295-318. DOI: 10.1111/j.1933-1592.2012.00647.x

did not know which particular I was in fact tracking and that I therefore did not know which particular I demonstratively intended to touch.

Notice that this is case where my perceptual capacities do not break down in a way that interferes with my ability to form demonstrative concepts and demonstrative intentions. Experience is still playing an enabling role for the formation of demonstrative intentions. Experience has, however, due to the introduction of a particular contextual defeater, lost its ability to justify beliefs about the experienced objects spatiotemporal identity and therewith its ability to justify my belief about which demonstrative intentions I am entertaining. In this case, perceptual knowledge of the object's spatiotemporal identity is part of what justifies my belief about my demonstrative intention.

\subsection{Constitution assumption}

Many philosophers think that an agent's knowledge of her own current action plays an essential role for the fact that the action is done intentionally. They would argue that it is in virtue (at least partly) of her knowledge of phoning a friend that an agent can truthfully be said to be phoning her friend intentionally. If the agent has no knowledge whatsoever of her own action, that is, if she is ignorant of the fact that she is doing something that causes a phone to ring in a friend's house, then this happening could not be described as something she is doing intentionally. If the agent is doing something intentionally, then she must be in possession of some kind of knowledge of some relevant aspect of her own action. The assumption here is that the agent's knowledge of her own action is constitutive for its being an intentional action. Call this the Constitution Assumption (CA). An objection to my proposal might be that it violates CA.

Let me spell out one reason for thinking that it violates CA before arguing that it does not. It appears natural to think that if the agent's knowledge is to be able to serve this constitutive function, then the agent's knowledge must somehow be intrinsic to the act. Acting intentionally requires knowing what you are doing, just as it requires that you intend to be doing it and that you are in control of what you are doing. This would explain the immediate character of the agent's knowledge. As O'Brien writes: “Perhaps 
Final draft. Grünbaum, T. (2013). Seeing what I am doing. Philosophy and Phenomenological Research, 86(2), 295-318. DOI: 10.1111/j.1933-1592.2012.00647.x

the most notable and problematic feature of our knowledge of our own actions is that it appears to be immediately available to the subject who is engaged in acting, and who is aiming to answer the question as to whether she is acting" (2007: 168).

Perception, the objection goes, would render this most notable feature unintelligible. First, perception is slow. Events are happening in the world. An arm is moving or a wall is being painted yellow. It takes time for the perceptual system to register such facts. First they have to be captured by the transducers, and then they have to be perceptually and, finally, semantically processed. Before this process is over the event is long gone: the arm has already been raised and the wall has been painted yellow. Second, perception picks up on and processes information about physical objects and events. We can perceptually register the consequences of our actions; one sees "what is happening at a given moment to the material one is working on" (Anscombe 2000: 89). Again, it would seem that perception makes one aware of the consequences of one's action rather than the action itself.

In sum, this objection is both phenomenological and metaphysical. Phenomenologically speaking, the agent's knowledge has an immediate character. So, if you think that perception is slow, then you might think that the agent's knowledge "does not seem to have to await the testimony of our perceptual faculties" (O'Brien 2007: 168). Metaphysically speaking, the conclusion of the above considerations could appear to be that if CA is true and the agent's knowledge is intrinsic and immediate, then it cannot be "acquired, or justified, via perceptual evidence in a given case" (O'Brien 2007: 169). Perceptions could only make us aware of the action as it is completed, it can make us aware of what we did; therefore it cannot be part of what makes the agent aware of what she is doing.

I do not think that this objection is very substantial. Here is why. First, it appears to beg the question. It assumes the truth of CA. But a good number of philosophers reject CA. ${ }^{14}$ They reject the claim that an agent's action is intentional only if she knows what she is doing. Davidson's (1980: 50, 91-92)

\footnotetext{
${ }^{14}$ Just to mention two prominent examples, Bratman (1987) and Mele (1992). For discussion, see Gibbon (2010).
} 
Final draft. Grünbaum, T. (2013). Seeing what I am doing. Philosophy and Phenomenological Research, 86(2), 295-318. DOI: 10.1111/j.1933-1592.2012.00647.x

famous example with a person succeeding in making ten carbon copies is thought to prove the point that an action can be intentional even if the agent is unaware of actually doing it. The agent only needs to know that she is trying to do it.

I think a more substantial reply to the objection (rather than just dismissing it on technical grounds) can be given. I want to remain neutral with respect to the truth of CA. My proposal should therefore be consistent with the idea that the agent's knowledge is "in the act", so to speak, and that is has this most notable feature of immediate availability. But why think that perception is an obstacle to this immediacy? The objection gives two reasons: perceptual processing takes time, so there will be a time-lag between the action and its perception; and perception is of the physical consequences of the action, so again perception lags behind. Neither of these is a good reason to deny perception a role in the agent's knowledge.

Phenomenologically speaking, perception does not lag behind. When have you ever experienced a time-lag between the event you are perceiving and your perceptual experience? Rarely, if ever, I submit. ${ }^{15}$ We do not experience any temporal gap between the movement of our arm and our experience of moving our arm. It might be that perceptual processing takes time. But this is the millisecond time of psychophysical measurement, not the time of lived experience. Furthermore, most actions take some time to perform. Carefully picking the right apple, writings one's name on a black board, clicking "send" after writing an email-message: these are all actions that are perceptually guided, where continuous perceptual experience is necessary for the completion of the action, and where the environmental consequences are part of the action. Such actions are evolving units where the perceptual experience of the object (the apple, the chalk and the board, and the cursor and the "send"button) is intrinsic to the

\footnotetext{
${ }^{15}$ We might experience a time-lag between modalities as when you see a gun being fired at a distance and only half a second later hear the shot. This, however, is different from experiencing a time-lag between the occurrence of an event and the experience of it.
} 
Final draft. Grünbaum, T. (2013). Seeing what I am doing. Philosophy and Phenomenological Research, 86(2), 295-318. DOI: 10.1111/j.1933-1592.2012.00647.x

action considered as a dynamically unfolding process. There is simply no good reason to think that the testimony of perception is something the agent has to await after having performed the action.

The agent's knowledge can be "in the act" and have the feature of immediate availability even if it is partly perceptually acquired and justified. If that is the case, then this objection does not succeed in showing that perceptual justification is inconsistent with CA.

\subsection{Conflicting causal roles}

It might be objected that the agent's knowledge could not be partly perceptual because perception has the wrong causal format. The agent's knowledge is knowledge of a description of her behaviour under which it is intentional. That is, it is a matter of grasping the content of one's intention as a description of one's behaviour. It is widely held that intention and perception have opposing causal roles. On the one hand, when an agent intends to do something, she represents the world as being a way which it is not (yet), and it is the causal role of the intention to cause and guide the behavioural process by which the agent transforms the world into the desired state. On the other hand, when an agent perceives something (an object or a fact), she is passively receiving information about the state of the world. It is the causal role of perception to affect the subject and enable her to acquire knowledge about mind-independent reality. Thus, when intending to do something, I grasp the represented fact as something I actively have to bring about. When perceiving something, I grasp the represented fact as something holding in the world and passively affecting me. On this way of setting up the issue, one might think that an agent cannot in any genuine sense perceive her own current intentional action - from the inside and as it is unfolding. Perception gives me knowledge of mind-independent facts: knowledge from the outside, as it were. I think the intuition here is that in intending and in the flow of acting the agent could not be relating to her own action in this way. ${ }^{16}$ If we assume CA, it seems obvious that the agent's knowledge could not be perceptual.

\footnotetext{
${ }^{16}$ See, for example, O’Shaughnessy (1980: ch. 9).
} 
Final draft. Grünbaum, T. (2013). Seeing what I am doing. Philosophy and Phenomenological Research, 86(2), 295-318. DOI: 10.1111/j.1933-1592.2012.00647.x

According to CA, the agent's knowledge is intrinsic and immediate, and not "from the outside" and after the fact.

One way to reply to this objection would perhaps be to reject the rigid opposition between activity and receptivity. This could perhaps be done by attacking the distinction at an architectural level (Hurley 1998) or at a personal level with respect to the content and phenomenology of perception (Noë 2004). I will leave aside such strategies. I think a much more promising strategy has been proposed by Roessler (2003). He argues that with respect to both nonconceptual ecological content and rational conceptual content, goals and intentions give rise to expectations - that is, beliefs about how the world will change. This type of mental state no longer seems to have a causal role that opposes it to perception. When I intend to pick up the phone, I am committed to bringing it about that my body moves in such a way that I pick up the phone, and this gives me reasons for expecting to see this happen. Building on this idea, Roessler argues that the causal roles of intention and perception are "perfectly compatible" (p. 400). I will not dwell on this issue and simply assume that Roessler is right and that there is no genuine incompatibility between intention and perception: intentions give rise to rational expectations about what one will experience when engaging in the execution of one's intention.

If there is no real incompatibility between intention and perception, then there appears to be no real hindrance to thinking that they could be integrated in the act itself, that is, during its execution.

\subsection{Propositions and inference}

It could be objected that the feature of immediate availability makes it implausible that the agent's knowledge could be inferentially acquired and that this would be a consequence of my proposal since perception and intention can be epistemically related only through an inference. Many philosophers think that intention and perception are states with propositional content. At least it might be thought that in the present context where perception is said to justify the agent's knowledge (belief) we must be talking about propositional states. A further reasonable assumption is that if two propositional states enter into a 
Final draft. Grünbaum, T. (2013). Seeing what I am doing. Philosophy and Phenomenological Research, 86(2), 295-318. DOI: 10.1111/j.1933-1592.2012.00647.x

justificatory relation, then they must be related by inference. If perception is epistemically involved in an agent's knowledge of her own action, then her knowledge of her own action is inferential because perception can only be inferentially related to one's intention. So, regardless of causal roles, if perception and intention are propositional states and the justificatory relation between propositions is inferential, then the following conditional seems to be true: if perception has a justificatory role in the agent's knowledge, then the agent's knowledge is inferential.

Again, this would seem to be in conflict with the "most notable" feature of immediacy, and, again, I want my proposal to be neutral on the issue of whether or not the agent's knowledge is inferential (with respect to some interesting personal level notion of inference). My proposal could be made consistent with the view that the agent's knowledge is non-inferential by rejecting the conditional. It might be true that two propositions can stand in a justificatory relation only by being inferentially related to each other. If intention and perception were both propositional states, then they could only be related by an inference. We might, however, follow many philosophers in claiming that perception is non-propositional. Many philosophers think that perceptual beliefs are acquired through and justified by perceptual experience but that they are non-inferentially acquired and justified. Another example could be the way in which a pain experience non-inferentially justifies a pain judgement. Similarly, in the case of an agent's belief about her own current basic intentional action, my claim would be that the agent's belief is noninferentially justified partly by her perceptual-attentional experience of the object of action. The agent simply grasps the content of her basic demonstrative intention as a description of her action and is noninferentially justified in doing so partly because of the continuous perceptual-attentional tracking of the object.

\subsection{A marginal case}

A final objection to my proposal might be the following: the proposal makes a valid observation about agents' intentional action with an object; but its significance is overstated. Object-oriented action is only a 
Final draft. Grünbaum, T. (2013). Seeing what I am doing. Philosophy and Phenomenological Research, 86(2), 295-318. DOI: 10.1111/j.1933-1592.2012.00647.x

small sub-class of human agency. The account does not generalize to everyday actions such walking, driving one's car, talking to someone, etc. What we want is a perfectly general account of human physical agency, and in such an account the agent's knowledge could not be perceptual.

I accept that maybe not all forms of physical action and agents' knowledge thereof could be said to involve perception in an epistemic way. I disagree, however, with the idea that a completely general account of action and agent's knowledge is a desideratum (or the only desideratum). Philosophers often attempt to construct completely general accounts (often in terms of necessary and sufficient conditions). In the case of human action such an endeavour is to some extent to be avoided. The phenomenon is too multi-faceted. The discussion in philosophy of action between non-observational and two-factor accounts of the agent's knowledge is often conducted as if this was an exclusive either-or for all forms of intentional action. This has hindered a serious consideration of the diversity and complexity of many forms of physical agency.

When this is said, there are reasons for thinking that object-directed intentional action as the execution of a basic intention (as the outcome of practical reasoning) is not a marginal case at all. It is an empirical fact, I claim, about humans (and probably other animals as well) that ordinarily our skilful action is a form of object-oriented action. Ordinarily, the most basic action-description of an agent's behaviour picks out her action as a visually controlled, object-oriented intentional action (for example, taking down this book from the shelf or pouring water into this cup). Our physical actions are spatial actions and often they involve or manipulate objects. We need to navigate through our immediate surroundings and we use tools to accomplish our goals. It just so happens that it is on the level of acting with or on physical objects that we can most often be said to have skills that we intentionally exercise. This fact establishes an important relation between perceptual attention and selection and execution of basic intentions. 
Final draft. Grünbaum, T. (2013). Seeing what I am doing. Philosophy and Phenomenological Research, 86(2), 295-318. DOI: 10.1111/j.1933-1592.2012.00647.x

\section{Final remarks}

Let me end this paper by briefly summing up the results of my argument. My starting point was a set of assumptions accepted by most contemporary Anscombean accounts of agents' knowledge. The first assumption is the following:

2.3. Assuming certain background conditions hold (skills, know-how, a minimally corporative world), the agent is entitled to grasp the content of her intention to do a basic action as a description of her intentional action.

The Anscombean account employs this claim in the explanation of why the agent's knowledge of her own intentional action is non-observational. Knowledge of action is non-observational because the agent knows her action by knowing her intention and knowledge of intention is non-observational. The account thus accepts the following two conditional.

2.4. If knowledge of intention is non-observational, then knowledge of action is non-observational.

2.5. If knowledge of intention is observational, then knowledge of action is observational. In this paper I have accepted all three claims.

In many situations an agent's basic intentional action will be an execution of her demonstrative intention. That is, her basic action will often be one where she intentionally does something to or with a particular object. In these situations, the agent is therefore (given 2.3) entitled to grasp the content of her demonstrative intention as a description of her intentional action.

Knowing one's demonstrative intention depends epistemically on knowing which object you intend to act on. This knowledge is observational. Knowing one's demonstrative intention depends on observation in the sense that one's belief about what one demonstratively intends to do is justified by experience of the relevant object. Given (2.5), in the case of demonstrative intentions, it follows that knowledge of action is observational.

Let me end by making a final remark about the notion of observation. Sometimes the worry motivating philosophers to claim that an agent's knowledge of her own intentional action is non- 
Final draft. Grünbaum, T. (2013). Seeing what I am doing. Philosophy and Phenomenological Research, 86(2), 295-318. DOI: 10.1111/j.1933-1592.2012.00647.x

observational is that the agent's knowledge is privileged. If the agent is doing something intentionally, she knows what she is doing in a way that is not immediately available to others. It is sometimes thought that if the agent's knowledge is observational, her knowledge would not be privileged. The way in which I have claimed that the agent has observational knowledge of her own demonstrative intention does not imply that the agent is observing herself and the material she is working on as an outside observer. It implies that she is in experiential contact with the object she intends to act on or with. Experience provides her with knowledge of which object she intends to act on. Without this experiential identification she would not be justified in thinking that she intends to $\phi$ with this $o$. This notion of observation and the role it plays in the agent's knowledge is perfectly consistent with the idea of privileged knowledge. ${ }^{17}$

\section{References}

Allport, A. (1993), Attention and control: Have we been asking the wrong questions?, in D. E. Meyer \& S. Kornblum (eds.), Attention and Performance XIV (pp. 183-218). Cambridge, MA: The MIT Press.

Anscombe, G.E.M. (1957/2000), Intention. Cambridge, MA: Harvard University Press.

Anscombe, G.E.M. (1979), Under a description, Noûs, 13: 219-233.

Bratman, M. (1987), Intention, Plans, and Practical Reason. Cambridge, MA: Harvard University Press.

Brewer, B. (1999), Perception and Reason. Oxford: Oxford University Press.

Brewer, B. (2000), Externalism and A Priori Knowledge of Empirical Facts, in C. Peacocke and P. Boghossian (eds.), New Essays on the A Priori (pp. 415-432) Oxford: Oxford University Press.

Burge, T. (1993), Content Preservation, Philosophical Review, 102: 457-488.

\footnotetext{
${ }^{17}$ For comments on a very early version of this paper, I am indebted to Johannes Roessler, Bill Brewer, and Jane Heal. I am equally grateful to Mikkel Gerken, Johan Gersel, Joel Krueger, Søren Overgaard, and Asbjørn Steglich-Petersen for helpful comments and discussions of later drafts. A reviewer for this journal deserves special mention for his or her careful comments. Research for this paper was funded by a grant from the Danish Research Council, FKK, project number 476100-50-30735.
} 
Final draft. Grünbaum, T. (2013). Seeing what I am doing. Philosophy and Phenomenological Research, 86(2), 295-318. DOI: 10.1111/j.1933-1592.2012.00647.x

Burge, T. (1998), Reason and the First Person, in C. Wright, B.C. Smith, and C. Macdonald (eds.), Knowing Our Own Minds (pp. 243-270). Oxford: Oxford University Press.

Campbell, J. (2002), Reference and Consciousness. Oxford: Oxford University Press.

Campbell, J. (2003), The Role of Demonstratives in Action-Explanation, in J. Roessler and N. Eilan (eds.), Agency and Self-Awareness. Oxford: Oxford University Press.

Carey, S., \& Xu, F. (2001), Infants knowledge of objects: Beyond object-files and object tracking, Cognition, 80: 179-213.

Davidson, D. (1980), Essays on Actions and Events. Oxford: Oxford University Press.

Enç, B. (2003), How We Act. Oxford: Oxford University Press.

Evans, G. (1982), Varieties of Reference. Oxford: Oxford University Press.

Falvey, K. (2000), Knowledge in Intention, Philosophical Studies, 99: 21-44.

Gibbon, J. (2010), Seeing what you're doing, in T. S. Gendler \& J. Hawthorne (eds.), Oxford Studies in Epistemology, Vol. 3. Oxford: Oxford University Press.

Ginet, C. (1990), On Action. Cambridge: Cambridge University Press.

Goldman, A. I. (1971), The individuation of action, Journal of Philosophy, 68: 761-774.

Hommel, B. (2005), Perception in action: multiple roles of sensory information in action control, Cognitive Processing, 6: 3-14.

Hornsby, J. (1980), Actions. London: Routledge \& Kegan Paul.

Hurley, S. (1998), Consciousness in Action. Cambridge, MA: Harvard University Press.

Kaplan, D. (1989a), Demonstratives, in J. Almog, J. Perry, and H. Wettstein (eds.), Themes from Kaplan (pp. 481-563). Oxford: Oxford University Press.

Kaplan, D. (1989b), Afterthoughts, in J. Almog, J. Perry, and H. Wettstein (eds.), Themes from Kaplan (pp. 565-614). Oxford: Oxford University Press.

McDowell, J. (1986), Singular Thought and the Extent of Inner Space, in P. Pettit and J. McDowell (eds.), Subject, Thought, and Context (pp. 137-168). Oxford: Clarendon Press. 
Final draft. Grünbaum, T. (2013). Seeing what I am doing. Philosophy and Phenomenological Research, 86(2), 295-318. DOI: 10.1111/j.1933-1592.2012.00647.x

Mele, A. (1992), Springs of Action. Oxford: Oxford University Press.

Moran, R. (2004), Anscombe on 'Practical Knowledge, in J. Hyman and H. Steward (eds.), Agency and Action: Royal Institute of Philosophy Supplement, 55: 43-68.

Neumann, O. (1990), Visual attention and action, in O. Neumann \& W. Prinz (eds.), Relationships between perception and action (pp. 227-267). Berlin: Springer Verlag.

Noë, A. (2004), Action in perception. Cambridge, MA: The MIT Press.

O’Brien, L. (2007), Self-Knowing Agents. Oxford: Oxford University Press.

O’Shaughnessy, B. (1980), The Will, II. Cambridge: Cambridge University Press.

Paul, S. (2009), How we Know What We're Doing, Philosophers' Imprint, 9: 1-23.

Peacocke, C. (1981), Demonstrative Thought and Psychological Explanation, Synthese, 49: 187-217.

Peacocke, C. (2003), Action: Awareness, Ownership, and Knowledge, in J. Roessler and N. Eilan (eds.), Agency and Self-Awareness (pp. 94-110). Oxford: Oxford University Press.

Pickard, H. (2004), Knowledge of Action without Observation, Proceedings of the Aristotelian Society, 104/3: 203-228.

Roessler, J. (2003), Intentional action and self-awareness, in J. Roessler and N. Eilan (eds.), Agency and SelfAwareness. Oxford: Oxford University Press.

Scholl, B. J. (2001), Objects and attention: The state of the art, Cognition, 80, 1/2: 1 - 46.

Scholl, B. J. (2007), Object persistence in philosophy and psychology, Mind \& Language, 22, 5: 563 - 591.

Scholl, B. J., \& Leslie, A. M. (1999), Explaining the infant's object concept: Beyond the perception/cognition dichotomy, in E. Lepore \& Z. Pylyshyn (eds.), What is cognitive science? (pp. 26 - 73). Oxford: Blackwell Publishers.

Setiya, K. (2008), Practical Knowledge, Ethics, 118: 388-409.

Styles, E. A. (1997), The Psychology of Attention. Hove: Psychology Press.

Xu, F. (1997), From Lot's wife to a pillar of salt: Evidence for physical object as a sortal concept, Mind and Language, 12: 365-392. 